\title{
LA JUSTICIA LABORAL EN LA
} PROVINCIA DEL CHACO. INNOVACIONES EN EL PROCEDIMIENTO*

\author{
LABOR JUSTICE IN THE \\ PROVINCE OF CHACO. \\ INNOVATIONS IN PROCESS
}

\section{JORGE GUSTAVO DAHLGREN}

Facultad de Ciencias Económicas

Universidad Nacional del Nordeste

ARGENTINA. 


\title{
RESUMEN
}

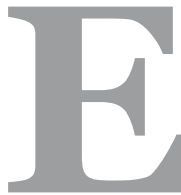

1 presente trabajo tiene por finalidad brindar un panorama del estado actual de del trámite impreso por la nueva legislación al procesal laboral en la Provincia del Chaco, mediante la instrumentación de la "audiencia de trámite", herramienta típica que caracteriza al procedimiento mixto. En tal cometido, se han revisado algunos aspectos importantes de trámite procesal regulado en la legislación anterior que tenía previsto un proceso escrito, señalándose los motivos que dieron lugar a las distintas reformas hasta llegar a la actual redacción del nuevo código procesal laboral. El sostenido incremento de judicialización de causas laborales a través de los años, han impuesto la necesidad de efectuar importantes modificaciones al proceso laboral, en base al obligatorio contacto personal y directo de las partes y el juez, con la finalidad de dar celeridad al trámite procesal. Si bien la oralidad en el procedimiento laboral sería ideal, en la práctica resulta de difícil implementación, en razón de la cantidad de tiempo que lleva la presencia personal del juez a cada una de las audiencias, sustrayéndolo de otras tareas también importantes derivadas de su función. Requiriendo la oralidad la asistencia personal de todos los interesados, facilita en gran medida la conciliación de intereses, aspecto ausente en los procesos escritos, motivo por el cual la legislación chaqueña ha optado por una solución intermedia acudiendo al procedimiento mixto instrumentado por medio de una "audiencia de trámite".

Palabras clave: proceso laboral mixto, audiencia de trámite, Chaco.

\begin{abstract}
This paper aims to provide an overview about the written procedure and its current status, influenced by the new legal procedure in Chaco Province, as a result of the "hearing process" instrumentation, which is a typical tool that characterizes the mixed procedure. Therefore, it has been reviewed previous legislation that provides some important aspects of written process. As a result, it's been noted the reasons that causes the law changes until it gets as we know it now. Over the years, the labor lawsuits increase and it has imposed changes in order to approach the people to the judge and also, to speed up the process. In one hand, oral proceedings would be ideal, but in the practice it is difficult to apply. That is so, because of the time that is required the judge's personal presence at every hearing, preventing them to work on other function's tasks.
\end{abstract}

\footnotetext{
"Este artículo fue producido en el marco del Proyecto de Investigación PI M002-2013 "Contextos de trabajo: entramados, poder y violencia. Estudios sobre organismos del estado, programas sociales, sector rural y cambio tecnológico que integra el autor y dirige la Dra. Ana Rosa Pratesi. El PI está acreditado por Resolución N 839/13 del C.S. de la UNNE.
} 
The interested people's physical presence on a trial improves the conciliation on both parts interests. Because of it, Chaco legislation has adopted an intermediate solution: the mixed procedure by legislating "Hearing Process".

Keywords: new mixed labor process, hearing process, Chaco.

\section{INTRODUCCIÓN}

El tema a exponer, tiene actual importancia, en atención a la lentitud que presentaba y presenta el desarrollo del proceso laboral en sede judicial. Esta cuestión que va en contra de los intereses del trabajador, que acude al servicio de justicia con la necesidad de contar con su crédito de modo urgente, para atender no sólo a sus necesidades de carácter alimentario, sino también las que corresponden a su núcleo familiar.

La nueva legislación ha otorgado un trámite mixto al proceso laboral, incluyendo también procesos especiales abreviados, como un modo de dar respuesta a esta situación.

\section{ANTECEDENTES}

La organización de la justicia del trabajo en la Provincia del Chaco tiene su origen en el año 1953 con la vigencia de la Ley $\mathrm{N}^{\circ}$ 30, modificada dos años más tarde por la Ley 113, posteriormente en el año 1960, se dicta la Ley 349.

Luego en el año 1979 comienza a regir la Ley $\mathrm{N}^{\circ}$ 2.384, reemplazando toda la legislación anterior, con una vigencia de más de treinta años, siendo esta la norma que más longevidad tuvo dentro de nuestra organización laboral adjetiva.

Esta última norma tenía regulado la implementación de un proceso judicial escrito, con la regulación de una "audiencia de conciliación", que en la gran mayoría de los procesos eran desistidas por los interesados, postergándose el reclamo del trabajador.

El plazo de duración de los procesos tenían un promedio de hasta diez años, contados desde el momento mismo de la interposición de la demanda hasta el dictado de una sentencia de primera instancia, aspecto que evidenciaba la necesidad de la modificación del proceso laboral.

Si bien el proceso escrito en un principio se había mostrado eficiente y rápido, el crecimiento de la población y el incremento del nivel de judicialización de los reclamos laborales, ha llevado a la revisión de algunos aspectos procesales. ${ }^{1}$

${ }^{1}$ Ley Provincial $N^{\circ} 2.383$ (Chaco) Procedimiento Laboral - Exposición de motivos. 
Es así que a mediados del año 2013, en un claro intento de abandonar el trámite del proceso escrito, la novedosa Ley 7.057 trae por primera vez la implementación de un proceso mixto, regulado en base a una nueva "audiencia de trámite", en reemplazo de la anterior "audiencia de conciliación”, que llegará a la práctica forense para radicarse definitivamente hasta la actualidad.

Cabe destacar que con la nueva "audiencia de trámite", no se ha alcanzado una oralidad plena del proceso laboral, solamente viene a presentar un nuevo sistema mixto, incorporando con la misma, algunas características propias del proceso oral al escrito.

Con las modificaciones se ha buscado celeridad procesal, para facilitar conciliaciones y para el caso de no arribar a un acuerdo, el tribunal tiene para depurar la prueba relevante, poniendo al proceso en condiciones de ser resuelto, entre otras cuestiones interesantes.

Ahora bien y como contrapartida, ocurre que el rápido avance del importante caudal de causas listas para resolver, encuentra un nuevo escollo que presenta la imposibilidad de dictar la importante cantidad resoluciones pendientes, postergándose de este modo el dictado de las sentencias.

Frente a esta situación, los tribunales intervinientes se veían obligados a dictar una providencia de estilo mediante la cual se informa la imposibilidad de llamar autos para el dictado de sentencia, pasando el expediente a integrar una "lista de espera" de acuerdo al orden cronológico de los pedidos de los profesionales y así es posible advertir causas con cinco años en lista de espera para ser sentenciadas.

Uno año más tarde la Ley $\mathrm{N}^{\circ} 7.434$, actualmente vigente viene a modificar todas las disposiciones anteriores y si bien mantiene el trámite del procedimiento mixto, suma nuevos procedimientos especiales para determinados casos como los accidentes de trabajo, medidas autosatisfactivas, entre otros institutos interesantes, agregando nuevas herramientas procesales para hacer frente a esta situación.

\section{3.- LA ORALIDAD EN EL PROCESO LABORAL}

El principio de oralidad "supone que si bien los actos constitutivos del proceso -demanda, contestación, reconvención- pueden ser redactados por escrito; la prueba habrá de ser recepcionada oralmente y de ser posible en el menor número de audiencias”. (Kees y Vispo, 2009, p. 68).

Así también se ha dicho que: "la oralidad permite que el juzgador pueda estar frente a las partes del proceso, a los testigos y a los peritos, percibiendo sus actitudes, gestos, palabras, que le permitan apreciar en forma directa y objetiva los hechos tal cual sucedieron en la realidad. En definitiva este principio permite y ayuda a esclarecer la verdad real por encima de la formal, siendo propia de los procedimientos judiciales de instancia única”2 (Brain, Córdoba, 2008, p. 37).

Ahora bien, vale recordar que la oralidad resulta de difícil instrumentación motivo por el cual, los procesos orales se encuentran previstos por muy pocas provincias. 
La implementación de este principio resulta incuestionable si los consideramos solo en relación a un proceso de manera individual, donde sus beneficios son evidentes.

$\mathrm{Al}$ respecto se ha entendido que las ventajas del mismo "consisten en la concentración de los actos procesales, en una o varias audiencias, en la eliminación de los traslados, de las notificaciones, en la mayor rapidez de los trámites, en impedir la delegación de la función judicial, en asegurar la inmediación del magistrados con las partes y los testigos, en el contacto directo con los elementos de prueba y en la mayor libertad de apreciación de esta” (Brain, 2008, p. 37).

Sin embargo la cuestión cambia con sólo compulsar la cantidad de causas judiciales que tramitan, resultando humanamente imposible dar atención y presencia personal del juzgador en cada una de ellas, teniendo presente que por cada año ingresan más de mil, consecuentemente la capacidad de respuesta seria prácticamente nula.

Para una mejor ilustración del tema cabe mencionar, que cada tipo de proceso tiene dentro de su desarrollo una audiencia que lo caracteriza, y de acuerdo al tipo de cada una de ellas varía sustancialmente el trámite que se imprime al mismo.

Así básicamente, podemos señalar que dentro del proceso escrito observamos la regulación de la "audiencia de conciliación", en el proceso mixto la "audiencia de trámite" y por último en el proceso oral la "audiencia de vista de causa".

En nuestro país existen diversidad de trámite de procesos laborales que van, desde los proceso escritos como el caso de la legislación nacional, los mixtos en las provincias del Chaco y Corrientes, mientras que la oralidad se la puede observar en las provincias de Buenos Aires y Formosa, sólo por citar algunos casos que ponen en relieve la disparidad en las regulaciones del proceso laboral.

Pero estas diferencias de trámite en el proceso también se advierte en los distintos fueros de la Provincia, pudiendo citar la vigencia del proceso escrito en el contencioso administrativo, el mixto tanto el civil y comercial como en el laboral, con la "audiencia de trámite" y oral en el de familia, con las "audiencia de vista de causa".

Ahora bien, el proceso laboral por su naturaleza, a diferencia del proceso de familia, requiere la realización de pruebas eminentemente técnicas, tales como pericias médicas, contables, informativas y compulsas de libros contables, entre otras.

Consecuentemente el debate probatorio requiere un mayor tiempo de dedicación y especialidad, para dilucidar cuestiones en que en variadas ocasiones son complejas.

A modo de ejemplo cabe citar el control de la confección de las planillas practicadas por las partes e incluso por el mismo tribunal, grado de incapacidad en casos de accidentes o enfermedades profesionales, aplicación de coeficientes que se actualizan constantemente, entre otras cuestiones.

Como se verá, la deseada oralidad que debería impregnar al proceso laboral, debe ser detenidamente analizada, caso contrario es posible encontrarnos con una mayor extensión temporal del proceso, tal lo advertido en la Provincia de Formosa. 


\section{4.- LA ORALIDAD Y SU BAJA EFECTIVIDAD}

La vigencia del principio de oralidad se advierte vigente en las provincias de Formosa ${ }^{3} \mathrm{y}$ en Buenos Aires ${ }^{4}$, procedimiento donde se precisan con claridad las reglas que regirán la "audiencia de vista de causa", alcanzando así este principio su máxima expresión.

De un simple repaso por dichas legislaciones, se puede advertir la brevedad de su contenido, destacando que en la Provincia de Formosa sólo alcanzan a noventa y un artículos, lo que de alguna manera viene a representar un claro recorte en las posibilidades defensivas de la parte patronal, no existiendo recursos ordinarios como por ejemplo el de apelación.

Resulta interesante señalar que en la primera circunscripción de la Provincia de Formosa, es de público y notorio que sólo se llevan a cabo aproximadamente ocho "audiencias de vista de causa" por semana, habiéndose dictando en el curso del año 2016, entre las tres Salas del Trabajo, solamente aproximadamente ciento setenta sentencias por año. ${ }^{5}$

Contrastando con la gran cantidad de causas que se inician por año, es posible observar una mayor demanda a una menor capacidad de respuesta.

Otro dato interesante es que, la mayor parte de los procesos orales es la gran cantidad de conciliaciones que se arriban durante el curso de la audiencia de vista de causa, pero sin embargo se advierte una considerable demora en fijarse, que en algunos casos puede llevar años.

Este aspecto, viene a obstaculizar la urgencia del reclamo laboral y lógicamente la voluntad de acuerdo pasa a depender de la fecha de fijación de audiencia de vista de causa.

\section{5.- LA INSTANCIA ADMINISTRATIVA COMO ALTERNATIVA}

\subsection{En la Provincia del Chaco}

La legislación procesal administrativa también se ha preocupado por brindar una solución rápida a los reclamos del trabajador, mediante la instrumentación de una instancia conciliatoria previa al reclamo judicial, concretamente en la sección relativa a los conflictos individuales del trabajo.

Se ha regulado a la instancia conciliatoria, mediante un breve procedimiento oral cuyo trámite, una vez iniciado, resulta de cumplimiento obligatorio en cuanto a su sustanciación, como medio alternativo para la resolución de conflictos. ${ }^{6}$

\footnotetext{
${ }^{3}$ L.P. $N^{\circ} 639$ (Formosa), art. 40

${ }^{4}$ L.P. N ${ }^{\circ} 11.653$ (Buenos Aires), art. 44

${ }^{5}$ López, A. E. (Entrevista del 14/02/17) Abogado. Matricula N 781 . Colegio de Abogados de Formosa.

${ }^{6}$ L.P. $\mathrm{N}^{\circ} 2959$ (Chaco), art. 16
} 
Se trata de un procedimiento sencillo, que se inicia optativamente a través de medio de un reclamo informal, pudiendo concluir mediando una homologación con eficacia de cosa juzgada administrativa. ${ }^{7}$

La competencia específica dentro de la Dirección Provincial del Trabajo como autoridad administrativa, corresponde al Departamento de Relaciones Laborales, previéndose la asistencia de dos o más conciliadores para destrabar la situación conflictiva y estimular el acuerdo siempre protegiendo activamente los derechos irrenunciables del trabajador. ${ }^{8}$

Sin embargo los lineamientos trazados por ley administrativa vigente, no han dado los frutos esperados y ello se advierte con sólo observar el creciente nivel de judicialización de conflictos laborales, que han llevado a la modificación del trámite de los procesos judiciales, tal lo ocurrido en nuestra provincia.

\subsection{En la Nación}

Previo a la interposición de todo demanda laboral, el intento conciliatorio resulta obligatorio y de efectuarse de manera obligatoria dentro de la informalidad del ámbito administrativo o sea el Ministerio de Trabajo, Empleo y Seguridad Social dependiente del Poder Ejecutivo Nacional, concretamente bajo la competencia del Servicio de Conciliación Obligatoria Previa (SECLO).

Sin perjuicio de su convalidación constitucional, por encontrarse sujeto a revisión Judicial posterior ${ }^{9}$, la experiencia indica que se ha señalado que no habría dado resultados satisfactorios.

En efecto, conciliaciones pueden llevarse a cabo por montos muy inferiores al que realmente corresponde, confección de planilla generalizada, sin adecuación al orden público laboral, circunstancia que en la práctica ha dado lugar al planteo de diversas nulidades procesales en sede judicial reclamándose diferencias no percibidas (Kesselman, 2013).

Este procedimiento oral previo, no resultaría recomendable, ya que representaría una verdadera instancia previa, facilitándose de este modo la prolongación del reclamo, desnaturalizándose el principio protectorio.

\section{6.- EL TRÁMITE EN LA ANTERIOR LEGISLACIÓN}

El trámite del proceso escrito, instrumentado por la Ley $\mathrm{N}^{\circ} 2383$ ha llevado a un virtual colapso de funciones de los juzgados laborales 1, 2 y 3 pertenecientes a la Primera Circunscripción Judicial, conforme los resultados de inspecciones realizadas (Lucas, Toledo, Franco, Modi, Ávalos, 2012).

\footnotetext{
${ }^{7}$ L.P. $\mathrm{N}^{\circ} 2959$ (Chaco), art 24

${ }^{8}$ Decreto Reglamentario N 1613/84 (Chaco) - Capítulo IV - Departamento Relaciones Laborales

${ }^{9}$ CNAT Sala $3^{\circ}(29 / 12 / 00)$ "Soverón, I. c/ Austral L. A. Cielos del Sur S.A.". Idem CSJN Fallos 244:248
} 
Dichos tribunales ya se habían visto superados en su capacidad de respuesta en relación al número de expedientes que pueden tramitar cada uno de ellos, imposibilitando el cumplimiento de la exigencia normativa relativo al cumplimiento de los plazos establecidos por la ley al Tribunal para el dictado de resoluciones. ${ }^{10}$

En respuesta a esta situación, la Ley $\mathrm{N}^{\circ} 7057$ ha introducido modificaciones a la Ley $\mathrm{N}^{\circ}$ 2383, introduciendo la "audiencia de trámite", habiendo arrojando los primeros resultados positivos.

El objetivo fue promover los intentos conciliatorios y el saneamiento del proceso, dejando al mismo en condiciones de ingresar a una segunda etapa pero ahora controvertida, donde nos encontramos con una serie de facultades concedidas por la normativa al juzgador.

En primer lugar se ha pretendido asegurar el contacto directo de las partes y el juez, con asistencia obligatoria, pretendiendo el avenimiento de intereses, como una medida para llegar a la conclusión del proceso, disminuyendo el volumen de causas judiciales. ${ }^{11}$

Una de las novedades radica en que, para el supuesto caso de fracasar los intentos conciliatorios, se confiere facultad al juez para seleccionar la prueba ofrecida, pudiendo denegar las improcedentes, superflua, o meramente dilatoria.

Entre ellas podemos citar las tendientes a simplificar la cuestión controvertida, mejorar el control, depurar pruebas, declarar la causa como de puro derecho u ordenar la producción para el caso de existir hechos debatidos que deban ser acreditados.

La posibilidad de la aplicación de sanciones para el supuesto caso de inasistencia de las partes interesadas, surge como una cuestión importante y distintiva, ya que en anterior normativa no se advertían estas previsiones.

Cabe puntualizar que la antigua "audiencia de conciliación”, no interrumpía el curso del proceso y podía ser fijada por el Tribunal entre el período comprendido entre la contestación de la demanda o bien vencido el plazo para hacerlo hasta el momento de la apertura de la causa a prueba y como no resultaba obligatoria la concurrencia de los interesados, era frecuentemente desistida.

\section{7.- EL ACTUAL PROCEDIMIENTO DE LA AUDIENCIA DE TRÁMITE}

Hasta el momento de la contestación de la demanda, no se ven cambios sustanciales al procedimiento, ahora bien, ocurrida ella o vencido el plazo para hacerlo, se establece un plazo de veinte días para que el Tribunal proceda a la fijación de la audiencia de trámite.

${ }^{10}$ L.P. $\mathrm{N}^{\circ} 2383$ (Chaco), art. 22

${ }^{11}$ L.P. $N^{\circ} 7507$ (Chaco) Fundamentos, $4^{\circ}$ párrafo. 
La anterior normativa, tenía prevista la fijación de la audiencia de conciliación hasta antes de la apertura de la causa a prueba, sin la asistencia obligatoria de las partes y del juez.

La nueva norma vigente trae la obligatoriedad de asistencia personal tanto de las partes como del juez, bajo pena de nulidad, siendo señaladas estas previsiones en dos artículos de la nueva norma, con la evidente intención de resaltar su importancia. ${ }^{12}$

Actualmente la función judicial se dirige a la facilitación de la negociación, con la finalidad de aproximar intereses en juego, por medio de la propuesta de fórmulas conciliatorias no vinculantes, sin que ello sea entendido como prejuzgamiento.

En la anterior redacción, para el caso de incomparecencia de una de las partes hacía nacer la facultad del tribunal para convocar a una nueva audiencia de conciliación en cualquier estado del proceso siempre que se haya estimado probable un acercamiento de intereses ${ }^{13}$, aspecto que dilataba varios años el trámite del proceso.

El cambio es sustancial y radica en que, para el supuesto caso de falta de justificación de la inasistencia se ha previsto la preclusión de las facultades que pueden ejercerse en forma oportuna en defensa de los intereses de las partes y también la discrecional aplicación de multas que prudentemente graduará el Tribunal.

\subsection{La conciliación en la audiencia de trámite}

Antes de la realización de la audiencia preliminar el Tribunal verifica el cumplimiento de los actos procesales necesarios previos, procediendo a analizar los hechos y verificar las pruebas aportadas por los interesados, pretendiendo en primer término lograr un acuerdo entre las partes.

Calificada doctrina ha admitido: "tener el particular convencimiento de que la conciliación, como método de autocomposición de los intereses de las partes en un litigio laboral, resulta -a todas luces- la más justa, porque ella es la querida por ellas" (Vitantonio, 2008, p. 417 y 418).

Para lograr su efectividad, es vital una clara narración de los hechos acontecidos, la exposición de los elementos probatorios con que cuenta y la confección de la planilla anexa al reclamo, en armonía con el diseño de la demanda, por medio de una intervención profesional letrada honesta.

Oídas por el tribunal y facilitadas las relaciones personales entre las partes, los intentos de conciliación, pueden consistir en la ilustración a las partes interesadas sobre los alcances de la audiencia e invitándolas a un avenimiento, incluso advirtiendo la posibilidad de llegar a un acuerdo parcial.

\footnotetext{
${ }^{12}$ L.P. N ${ }^{\circ} 7.057$ (Chaco), art. 1

${ }^{13}$ L.P. N ${ }^{\circ} 2.383$, art. 84 (anterior redacción, antepenúltimo párrafo)
} 


\subsubsection{Correcta narración de los hechos}

La promoción de la acción debe contener una clara y correcta narración con una concreta invocación de los hechos considerados más trascendentes para la revisión histórica y dilucidación de la causa.

Se debe otorgar al tribunal información conducente a para la solución del litigio como por ejemplo sería la denuncia de la extensión de la jornada laboral ${ }^{14}$, inicio, ruptura y forma de la relación laboral, registración, categoría, diferencia de haberes, identificación de la patronal, remuneración, entre otros (Dahlgren, 2011, p. 337).

\subsubsection{Reclamos de montos razonables}

La adecuada determinación inicial del monto del reclamo debe reflejar la realidad del contenido de la relación laboral, posibilita en gran medida la llegada de un acuerdo transaccional.

De lo contrario, se puede llevar a un aumento injustificado de las esperanzas de un resultado que no sería justo, generando expectativas inconsistentes en el ánimo del trabajador.

Un aspecto importante en esta cuestión, es el adecuado contraste de los parámetros propuestos por las partes, con los montos mínimos y máximos en caso de eventual prosperidad de la acción.

Las partes deben detallar los rubros en que se componen las planillas a sus justos límites, sin abultarlos de manera desmedida, ni reclamar indemnizaciones improcedentes, rubros o multas derogadas, o cualquier otra cuestión que pueda prestar a confusión.

El uso desaprensivo de la jurisdicción, hace procedentes la aplicación de sanciones por temeridad y malicia ${ }^{15}$, como también el de la pluspetición inexcusable. ${ }^{16}$

\subsubsection{Cuestiones afectivas}

Son aquellos vínculos que se generan entre las partes del contrato laboral, como por ejemplo alguna sensibilidad influida sobre el ánimo del trabajador derivado del agotamiento que puede traer el hecho recibir órdenes que las considerar inapropiadas desproporcionadas en cuanto a su modalidades, o en algunas ocasiones ofensivas o incluso agresivas y que puede ocasionar algún grado de animosidad contra la otra parte.

Por lo general surgen cuando se debaten vínculos laborales extendidos en el tiempo, empeñándose una parte importante del tiempo de la audiencia de trámite, perjudicando su efectividad y los fines como también la normal administración de justicia.

${ }^{14}$ CNAT Sala VIII (16/09/08) "Carranza Cristian Andrés c/ American Guard S.R.L. s/ Despido.

${ }^{15}$ L.P. $\mathrm{N}^{\circ} 2383$ (Chaco), art. 24

${ }^{16}$ L.P. $N^{\circ} 968$ (Chaco), art. 72 
Cuando dentro la estrategia defensiva se encuentra el planteo de estas cuestiones, solo debería tener la trascendencia necesaria cuando aporten datos tendientes al esclarecimiento de la verdad real de los hechos invocados.

En todo momento es dable recordar que la actividad jurisdiccional sólo se encamina a restablecer el desequilibrio patrimonial originado en un vínculo laboral, dejando fuera de su órbita todas las vivencias que la relación laboral trajo aparejada.

\subsubsection{Derecho aplicable}

Si bien resulta necesario señalar el derecho que se pretende aplicable para cada caso particular, debe ser citado por las partes, en definitiva el protagonismo sobre esta cuestión siempre corresponde al tribunal.

Debemos tener presente que el juez se encuentra facultado a resolver incluso "extra petita" ${ }^{17}$, pero solamente con respecto a aquellas cuestiones que hayan sido materia de litigio. ${ }^{18}$

\subsection{Supuesto de falta de conciliación}

Fracasados los intentos conciliatorios, la audiencia de trámite continúa su curso, ingresando en una etapa que se podría llamar controvertida, donde el Juez cuenta con la facultad de determinar los hechos relevantes para ordenar sobre ellos la producción de la prueba.

En este estado la tarea del Tribunal cambia, encaminando su actividad en la determinación de las pruebas que resultan necesarias, pretendiendo disminuir los tiempos procesales y el caudal de las actuaciones judiciales, dejando atrás las fórmulas conciliatorias.

\subsubsection{Selección de Prueba}

Puede desestimar la producción de la prueba superflua pero luego de efectuada la selección, la actividad debe dirigirse a reducir la actividad probatoria en base a los hechos alegados $^{19}$, pudiendo depurar los elementos que considera necesarios para la acreditación de los mismos.

Debemos tener presente que: "no podrán producirse pruebas sino sobre hechos que hayan sido articulados por las partes en sus escritos respectivos. No serán admitidas las que fueren manifiestamente improcedentes o superfluas o meramente dilatorias". ${ }^{20}$

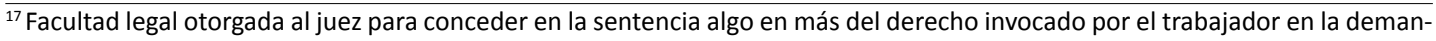
da, para evitar renuncias a créditos esenciales y alimentarios.

${ }^{18}$ L.P. $N^{\circ} 2383$ (Chaco), art. 128 (último párrafo)

${ }^{19}$ L.P. $N^{\circ} 7434$ (Chaco), art. 188, ap. a) Conciliación.

${ }^{20}$ L.P. N ${ }^{\circ} 968$ (Chaco), art. 342.
} 
El despacho saneador ${ }^{21}$, representa una alternativa procesal de utilidad derivada de las facultades de dirección e impulso ${ }^{22}$ del proceso conferida al Tribunal tendiente a promover la conciliación.

Se trata de "un instituto procesal de ineludible cumplimiento, que impone al juez la depuración de la demanda y los actos relativos al proceso, conformes los presupuestos procesales y a los requisitos de derecho de acción, la subsanación de errores formales, y la producción de prueba relevante y pertinente, de modo que permita y asegure al magistrado que ha de conocer y decidir sobre el fondo dictar una sentencia conforme a derecho y justicia” (Kees y Vispo, 2009, p. 70).

Esta herramienta procesal pretende acercar otros elementos conducentes para un eventual acuerdo, dejando de lado el planteo de eventuales nulidades y encausando la actividad jurisdiccional. ${ }^{23}$

De este modo se evita que el desistimiento de prueba represente la renuncia alguna de derechos vitales del trabajador (Dahlgren, 2011, p. 191).

El cuarto intermedio resulta un elemento útil para posibilitar el análisis de las propuestas conciliatorias y la recepción de mandatos concretos y reflexivos de los respectivos mandantes ya sea proveniente del trabajador o empleador, a sus letrados.

El beneficio de la confidencialidad que ampara a los profesionales en la labor conciliadora se presenta como un elemento trascendente durante el periodo de negociación, especialmente cuando, discretamente, hacen notar a sus representados las evidencias que surgen como incontestables de acuerdo al material probatorio aportado.

\subsubsection{Las Comunidades de Prueba}

La posibilidad de conformar comunidades de pruebas, especialmente a las referidas a los pedidos de informes a las distintas reparticiones públicas o bien a instituciones privadas, colabora en la reducción de los tiempos procesales.

De este modo se elimina la posibilidad de eventuales planteos de negligencia, transformando de interés común para los interesados su producción.

Por otra parte también se advierte que, con la determinación de la comunidad de pruebas, se desvanecen las posibilidades de algunos planteos de caducidad como por ejemplo de la prueba informativa ${ }^{24}$, pericial, reconocimiento judicial ${ }^{25}$, por lo que hasta no contarse con su producción, incluso vedaría a las partes de la posibilidad del planteo de caducidad de instancia, en razón del principio de buena fe que debe imperar en el proceso. ${ }^{26}$

\footnotetext{
${ }^{21}$ L.P. $\mathrm{N}^{\circ} 2383$ (Chaco), art. 25

${ }^{22}$ L.P. N $\mathrm{N}^{\circ} 7434$ (Chaco), art. 41

${ }^{23}$ CAT, Sala I, Rcia, Chaco (25/08/88) "Banco del Chaco c/ Olivera R. y otro s/ Actualización de Planilla”. Jueces: Dosso - Facal de Marchi.

${ }^{24}$ L.P. $\mathrm{N}^{\circ} 2383$ (Chaco), art. 111

${ }^{25}$ L.P. $\mathrm{N}^{\circ} 2383$ (Chaco), art. 125

${ }^{26}$ CNACC, Sala $3^{\circ}$ (18/10/95) “Vera J. C. c/ Estado Nacional - Ministerio del Interior Policía Federal Argentina s/ Accidente”. Expte. N 1.756/92 Jueces: Amadeo - Bulygin - Vázquez.
} 
Ahora bien, se entiende distinta la situación de las demás pruebas que conservan el interés individual en su diligenciamiento, tal el caso de la declaración de los testigos y absolución de posiciones, en cuanto a la confección de los proyectos de cédulas, elaboración y presentación de los respectivos pliegos, petición de conducción por la fuerza pública para el caso de los testigos ausentes sin justificación, etc., todas cargas que incumben a quien ha ofrecido la misma. ${ }^{27}$

Dispuesta la apertura de la causa a prueba, fija la fecha de producción de las pruebas testimonial y en caso de ser necesario requiere explicaciones a los peritos intervinientes.

Una vez producidas las actuaciones, se procede a la suscripción del acta por las partes interesadas, inmediatamente luego del proveído de las pruebas que han dispuesto producirse, pretendiéndose la optimización del tiempo de producción de la prueba, ajustando sus límites a términos razonables.

Ahora bien si la producción de pruebas no fuera necesaria, el tribunal puede disponer la declaración de puro derecho, lo que dejaría a la causa a punto de ser resuelta, unos días después de la finalización de la audiencia de trámite.

Con este tipo de actividades procesales derivadas de la audiencia de trámite se imprime celeridad al proceso permitiendo el dictado de sentencias en el plazo de "un año o año y medio, contra los seis, siete y hasta diez, que solía demorarse con el antiguo esquema de trabajo. La implementación de la audiencia preliminar significó la depuración de las pruebas ofrecidas por las partes en un promedio del 50\%” (Fernández, 2012).

Para el caso de constatar incomparecencia de las partes interesadas en el proceso, de acuerdo a su prudente criterio decide sobre su reconocimiento de los hechos, la aplicación de los apercibimientos de $l \mathrm{y}^{28} \mathrm{y}$ multas ${ }^{29}$.

\subsubsection{Caso de despido}

Ante el planteo de negación de la relación laboral alegado en la contestación de la demanda, no tendría sentido alguno ordenar la producción de determinadas pruebas impertinentes tales como las informativa y/o periciales

En efecto, a simple vista resultaría evidente la falta de relación del planteo efectuado con la realidad presentada por hechos controvertidos, por lo que resultarían inconducentes para la dilucidación de la causa.

Solamente resulta útil rescatar aquellos hechos que puedan aportar datos importantes sobre cuestiones trascendentes expuestos por los interesados.

Así también, puede darse el supuesto en que la defensa de la parte empleadora no niegue el vínculo laboral alegado por el trabajado, pero resulten controvertidas determinadas condiciones laborales, como por ejemplo la cuantía de la remuneración, categoría, etc.

\footnotetext{
${ }^{27}$ L.P. $N^{\circ} 968$ (Chaco), art 362

${ }^{28}$ L.P. $\mathrm{N}^{\circ} 7434$ (Chaco), art. 188

${ }^{29}$ L.P. N ${ }^{\circ} 969$ (Chaco), art. 338 bis
} 
La práctica enseña que en varias oportunidades, las organizaciones sindicales, demoran en contestar los pedidos de informes referidos a los índices requeridos por el Tribunal, específicamente en lo relativo a las escalas salariales vigentes de acuerdo al Convenio Colectivo aplicable que se puede pretender invocar, debido al cúmulo de sus actividades.

En este aspecto toma relevancia la actividad diligente del Tribunal en la búsqueda de estos datos que son de público conocimiento y pueden ser conocidos de manera sencilla, por ejemplo por medio de una simple comunicación telefónica o comunicación por correo electrónico, entre otras cuestiones.

\subsubsection{Caso de accidentes de trabajo o enfermedades}

En estos supuestos de donde se reclaman indemnizaciones por estos supuestos generalmente graves para la salud, en la misma audiencia de trámite el Juez puede ordenar la producción de pruebas de manera anticipada, en relación específica con los hechos propuestos y debatidos, efectuando un orden de prelación de acuerdo a su natural prioridad.

En varias ocasiones se puede advertir determinaciones incorrectas de porcentajes de incapacidad, siendo necesario pasar a cuartos intermedios, donde los profesionales intercambian datos identificatorios, (números telefónicos, correos electrónicos, etc.) pero debiendo continuar el desarrollo de la audiencia a la mayor brevedad, dentro de la semana siguiente en la medida de lo posible.

Ahora bien, en algunas causas se ha procurado la pronta realización de prueba relevante "por ejemplo la pericial médica en los casos de accidente de trabajo, cuando se detecta gravedad en las lesiones". ${ }^{30}$

El tribunal en uso de sus facultades de investigación puede seleccionar los puntos de pericia que considere útiles, ordenando otras medidas probatorias, en cualquier estado de la causa con la finalidad de establecer la verdad real de los hechos. ${ }^{31}$

\section{8.- REFLEXIONES FINALES}

Con la vigencia de la nueva Ley $\mathrm{N}^{\circ} 7434$, se mantiene la instrumentación de la audiencia de trámite, ya prevista por la anterior legislación ${ }^{32}$, pero con la introducción de nuevos institutos procesales interesantes.

\footnotetext{
${ }^{30}$ Superior Tribunal de Justicia (Chaco) (03/09/12), Acuerdo Extraordinario N ${ }^{\circ}$ 3. Jueces: Lucas M., Toledo R. - Franco R. - Modi M.- Avalos R. (Datos obtenidos de Inspección Anual Ordinaria a los Juzgados del Trabajo Nros. 1, 2 y 3 de la Ciudad de Resistencia, Provincia del Chaco.

${ }^{31}$ L.P. $\mathrm{N}^{\circ} 7434$ (Chaco), art. 41

${ }^{32}$ L.P. $N^{\circ} 2383$, modificada por la L.P. N 5057
} 
Podemos citar la incorporación de los procedimientos especiales, para el caso de los accidentes de trabajo, la instrumentación de las medidas autosatisfactivas, confección de planillas a cargo del tribunal, entre otras medidas que sin duda requieren un estudio especial y pormenorizado ajeno al objeto del presente trabajo.

Una cuestión llamativa es la eliminación de la prueba confesional también conocida como absolución de posiciones de los sujetos del proceso, considerada como una prueba de las conocidas como "orales" aptas para realizarlas en este tipo de audiencias, pero sin embargo no existe referencia concreta a ellas.

No debemos perder de vista el protagonismo que juegan las pruebas orales dentro del proceso laboral, en atención al modo informal en que se desarrollan las generalidades de las relaciones del trabajo, recordando que en caso de tenerse por confeso al demandado, surge la posibilidad de comenzar la ejecución del crédito líquido reconocible.

Por otra parte y como una medida para acompañar esta serie de modificaciones procesales y dar la posibilidad de dictar resoluciones al gran cumulo de causas, se ha puesto en funcionamiento el Juzgado Laboral $\mathrm{N}^{\circ} 4$ para la Primera Circunscripción judicial y el Juzgado Laboral $\mathrm{N}^{\circ} 2$ en la Segunda, los cuales ya se encuentran con un gran verdadero cúmulo de tareas, que con el transcurso de los años lógicamente se verán incrementados, en tanto las restantes circunscripciones judiciales o sea la tercera, cuarta y quinta aún se encuentran en el mismo estado, dos de ellas incluyendo a la justicia laboral dentro de los tribunales universales.

Sin embargo al respecto cabe puntualizar que la intención de lograr celeridad en el procedimiento, no debe agotarse con la instrumentación de un proceso mixto mediante la implementación de la audiencia preliminar, junto con otros procedimientos especiales.

Como resulta lógico, la celeridad lograda hasta el momento, trae como consecuencia el aumento de números de causas a resolver, demandando mayor capacidad de resolución tanto desde el punto de vista cuantitativo como cualitativo.

Estas nobles intenciones también deberían ser acompañadas con la adecuada provisión de recursos humanos y respectiva infraestructura, las distintas circunscripciones, cambio de modalidad en la prestación de servicios de los empleados judiciales.

En un futuro próximo es posible pensar en un inminente aumento de la cantidad de causas que irán posicionándose en estado de dictar resolución, lo que ha lleva a pensar en la necesidad de la creación de nuevos juzgados laborales.

Así también destacar que todos y cada uno los tribunales del Trabajo, deben contar con suficientes recursos humanos y técnicos para dar respuesta concreta a esta situación.

Concluyendo sería necesario, abrir el debate en cuanto a elevar la cantidad de juzgados a seis en la Primera Circunscripción Judicial, tres para la segunda, pensando también en la especialización del fuero laboral para cada jurisdicción. 


\section{REFERENCIAS BIBLIOGRÁFICAS}

Brain, D. Derecho Procesal del Trabajo, Editorial Advocatus, Córdoba.

Dahlgren, J. G. Procedimiento Laboral del Chaco - Ley N 2383 p. 337, Librería de la Paz, Resistencia, Chaco, 2011.

Fernández, A. M. (Juez del Trabajo $\mathrm{N}^{\circ} 1$ - Resistencia Chaco) Audiencias preliminares y división de tareas. Juzgados laborales cambian rutina para reducir la litigiosidad. Sitio web: http://www.datachaco.com/noticias/view/10310 (Recupero: 30/10/12)

Kesselman, P. - Ex Presidente del Colegio de Abogados de la Capital Federal (05/o9/13) Disertación en Jornada Preparatoria de Derecho Procesal Laboral.

Kees, A. y Vispo G. Código Procesal Civil y Comercial de la Provincia del Chaco. Comentado y Anotado, Tomo II, Editorial Contexto. Resistencia, Chaco, 2009.

Lucas M. L. - Toledo R. - Franco R, - Modi M. - Ávalos R. (Jueces del Superior Tribunal de Justicia - Chaco) Nuevo juzgado laboral desde 2013. Publicado en Sitio web: http://www. datachaco.com (recupero: 05/11/12).

Vitantonio N. - Director y Eguren M.C. Código Procesal Laboral de la Provincia de Santa Fe. Comentado y Anotado con el CPL de Corrientes. $1^{\circ}$ Reimpresión. Nova Tesis Editorial Jurídica. Rosario, Santa Fe, año 2008.

\section{SIGLAS:}

L.P.: Ley Provincial

CNAT: Cámara Nacional de Apelaciones del Trabajo

CAT: Cámara de Apelaciones del Trabajo

CNACC: Cámara de Apelaciones en lo Civil y Comercial 


\section{CURRICULUM VITAE}

\section{Jorge Gustavo Dahlgren}

Abogado. Facultad de Derecho, Ciencias Sociales y Políticas (UNNE). Especialista en Derecho Procesal. Facultad de Derecho (UNNE). Especialista en Seguridad Social, Facultad de Derecho (UNNE). Doctor en Derecho Público, Política y Gobierno Facultad de Derecho (UNNE). Profesor Adjunto por Concurso de Derecho Administrativo y Procesal Laboral (UNNE). Profesor de Posgrado Invitado - Facultad de Derecho y Ciencias Políticas y Sociales. (UNNE). Docente Investigador. Secretaría de Ciencia y Técnica (UNNE). Integrante de la Comisión Reformadora del Código Procesal Laboral del Chaco. Agente Fiscal No 12 - Fuero Civil, Comercial y Laboral (Cargo actual). Juez Subrogante del Tribunal Electoral - Provincia del Chaco (Período 2010 a 2012 y 2014 a 2016). Jurado en Concursos de Cargos Docentes - Facultad de Ciencias Económicas (UNNE). Miembro Titular en Comisiones Examinadoras en Concurso de Cargos (Consejo de la Magistratura).

dahl2828@hotmail.com 